\title{
Sequence analysis of pqq genes required for biosynthesis of pyrroloquinoline quinone in Methylobacterium extorquens AM1 and the purification of a biosynthetic intermediate
}

\author{
Hirohide Toyama, ${ }^{1}$ Ludmila Chistoserdova ${ }^{1}$ and Mary E. Lidstrom ${ }^{1,2}$
}

Author for correspondence: Mary E. Lidstrom. Tel: +1206 616 5282. Fax: +1 2066165721. e-mail: lidstrom@cheme.washington.edu

Departments of Chemical Engineering ${ }^{1}$ and

Microbiology², University of

Washington, Seattle,

WA 98195, USA

\begin{abstract}
Methylobacterium extorquens AM1 produces pyrroloquinoline quinone (PQQ), the prosthetic group of methanol dehydrogenase. Two gene clusters have been shown to be required for PQQ biosynthesis in this micro-organism and complementation analysis has identified seven pqq genes, pqqDGCBA and pqqEF. The DNA sequence of pqqDGC' was reported previously. This paper reports the sequence of the genomic region corresponding to pqqC'BA. For consistency, the nomenclature of pqq genes in Klebsiella pneumoniae will be followed. The new nomenclature for pqq genes of $M$. extorquens AM1 is pqqABCDE and pqqFG. In the genomic region sequenced in this study, two open reading frames were found. One of these encodes PqqE, which showed high identity to analogous pqq genes in other bacteria. PqqE also showed identity to MoaA and NifB in the $\mathrm{N}$-terminal region, where a conserved CxxxCxYC sequence was identified. The sequence of the second open reading frame covered both the $p q q C$ and $p q q D$ regions, suggesting that both functions were encoded by this gene. It is proposed to designate this gene pqqCID. The deduced amino acid sequence of the pqqCID product showed identity to PqqC of $K$. pneumoniae and Pqql of Acinetobacter calcoaceticus in the N-terminal region, and to PqqD of $K$. pneumoniae and Pqqll of $A$. calcoaceticus in the C-terminal region. A fragment of $M$. extorquens AM1 DNA containing only pqqCID produced a protein of $42 \mathrm{kDa}$ in Escherichia coli, which corresponds to the size of the deduced amino acid sequence of PqqC/D, confirming the absence of a separate pqqD. This genomic region complemented the growth of pqqC mutants of $M$. extorquens AM1 and Methylobacterium organophilum DSM 760 on methanol. As previously reported for pqq genes of $K$. pneumoniae, a pqqC mutant of $M$. extorquens AM1 produced an intermediate of PQQ biosynthesis, which was converted to $P Q Q$ by incubation with a crude extract from E. coli cells expressing PqqC/D. The intermediate was found in both crude extract and culture supernatant, and it was purified from the crude extract. The PqqC/D enzyme reaction appeared to require molecular oxygen and reduced nicotinamide adenine dinucleotides.
\end{abstract}

Keywords: PQQ, pyrroloquinoline quinone, biosynthesis, methylotrophs

\section{INTRODUCTION}

Pyrroloquinoline quinone (PQQ) is the prosthetic group of several bacterial enzymes, including methanol de- hydrogenase of methylotrophs and the glucose dehydrogenase of a number of bacteria (Anthony, 1993; Matsushita \& Adachi, 1993). Genes involved in PQQ synthesis have been cloned from Acinetobacter calcoaceticus

Abbreviation: PQQ, pyrroloquinoline quinone.

The GenBank accession numbers for the sequences determined in this work are: L25889 for pqqAB and the $5^{\prime}$ part of pqqC/D, and U72662 for the $3^{\prime}$ part of $p q q C I D$ and $p q q E$. 
(Goosen et al., 1989), Klebsiella pneumoniae (Meulenberg et al., 1992), Pseudomonas fluorescens CHA0 (Schnider et al., 1995), Methylobacterium organophilum DSM 760 (Biville et al., 1989) and Methylobacterium extorquens AM1 (Morris et al., 1994). In A. calcoaceticus, five genes were identified and sequenced, designated IV, V, I, II and III (Goosen et al., 1989). In K. pneumoniae, genes analogous to those were identified and designated $p q q A B C D E$, and in addition a sixth gene was found immediately downstream of $p q q E$, designated pqqF (Meulenberg et al., 1992). In Methylobacterium strains, a five-gene cluster (designated pqqDGCBA) was identified by complementation analysis (Biville et al., 1989; Morris et al., 1994), and sequence data from $M$. extorquens AM1 showed that the first three of these genes ( $p q q D G C)$ were analogous to pqqABC of K. pneumoniae (Morris et al., 1994). In $P$. fluorescens, genes analogous to $p q q F A B$ of $K$. pneumoniae have also been sequenced (Schnider et al., 1995). In all four sequences, a small gene is present that encodes a peptide of 22-29 amino acids, which contains conserved tyrosine and glutamate residues. Since tyrosine and glutamate are the probable precursors for PQQ synthesis (van Kleef \& Duine, 1988; Houck et al., 1991), it has been proposed that this peptide is the precursor from which PQQ is synthesized (Goosen et al., 1992). However, the biochemical steps of PQQ synthesis are still unknown.

Velterop et al. (1995) examined PQQ synthesis in vitro. A series of experiments was carried out in which cell extracts of Escherichia coli containing all but one of the Pqq proteins were combined with those containing the missing Pqq protein. PQQ was produced in only one of these sets, that involving PqqC. E. coli cells containing a clone encoding all but the PqqC protein apparently produced an intermediate of PQQ, found both in the culture medium and in the cells. However, the amount of the intermediate was low and it was unstable.

In the work reported in this paper, the genomic region of $M$. extorquens AM1 proposed to contain $p q q C^{\prime} B A$ was sequenced. In order to develop a consistent $p q q$ nomenclature, we followed the nomenclature of $p q q$ genes in K. pneumoniae (Meulenberg et al., 1992), which changes all of the $M$. extorquens AM1 pqq gene names except $p q q C$ (see Table 2). In the sequenced region, we found only two open reading frames (ORFs), $p q q C / D$ and pqqE. PqqC/D in M. extorquens AM1 appears to be a fusion of two Pqq proteins found in other bacteria, for instance, $\mathrm{PqqC}$ and $\mathrm{PqqD}$ in K. pneumoniae. A mutant of $M$. extorquens AM1 lacking PqqC/D produced an intermediate of PQQ as in the case of $K$. pneumoniae, but in much higher amounts. This intermediate was purified from the cell extract of the $p q q \mathrm{C}$ mutant of M. extorquens AM1.

\section{METHODS}

Bacterial strains and culture conditions. Strains and plasmids are listed in Table 1. Methylobacterium extorquens AM1rif and its mutant EMS12 were used as the wild-type and the
pqqC mutant strain, respectively (Morris et al., 1994). Cells were grown as described previously, using $0.2 \%$ succinate, $0.2 \%$ methylamine hydrochloride plus $0.2 \%$ or $0.5 \%$ methanol (Morris et al., 1994). Escherichia coli DH5 $\alpha$ harbouring pHT1KSac19f (see below) was cultured at $37^{\circ} \mathrm{C}$ in Luria broth containing $50 \mu \mathrm{g}$ ampicillin $\mathrm{ml}^{-1}$ to stationary phase.

DNA manipulations. Plasmid DNA from E. coli strains was prepared as described by Sambrook et al. (1989). Restriction enzyme digestion, DNA ligation and other DNA modifications were performed according to the vendors' recommendations.

DNA sequencing. A HindIII-PstI fragment was sequenced on both strands using the pUC universal and reverse primers and primers based on the determined sequences. Sequencing reactions and analyses were performed at the Sequencing Core Facility, California Institute of Technology, on an ABI 373A automated sequencer (Applied Biosystems). Oligonucleotides used for sequencing were synthesized at the Biopolymer Synthesis \& Analysis Resource Center at California Institute of Technology. Homology analyses were carried out using the Genetics Computer Group (GCG) program.

Plasmid construction. A $1.3 \mathrm{~kb} K p n \mathrm{I}-\mathrm{SacI}$ fragment containing $p q q C / D$ was blunted with T4 DNA polymerase and then ligated into the HincII site of pUC19. pHT1KSac19f, in which $p q q C / D$ is under the control of the lac promoter, was identified by restriction mapping. From pHT1KSac19f, a $1.3 \mathrm{~kb} \mathrm{BamHI}-$ Pst I fragment was isolated and ligated with pRK310, a broad-host-range vector (Ditta et al., 1985). pHT1KSac18 was a pUC18 derivative having the KpnI-SacI fragment in the opposite orientation to pHT1KSac19f (pqqC/D opposite to the lac promoter).

Preparation of crude extracts and culture supernatant. EMS12 was grown on minimal medium containing methylamine plus methanol to early stationary phase and $E$. coli $\mathrm{DH} 5 \alpha$ (pHT1KSac19f) was grown on LB medium containing ampicillin for more than $24 \mathrm{~h}$. Cells and culture supernatant were separated by centrifugation at $4000 \mathrm{~g}$ for $5 \mathrm{~min}$ at $4{ }^{\circ} \mathrm{C}$. Culture supernatant was filtered further with a $0.22 \mu \mathrm{m}$ filter when used in the assay for the intermediate. M. extorquens AM1 cells and E. coli DH5 $\alpha$ (pHT1KSac19f) cells were washed and suspended in $50 \mathrm{mM}$ potassium phosphate buffer $(\mathrm{pH} 7 \cdot 0)$ at a concentration of $1 \mathrm{~g}$ wet cells per $10 \mathrm{ml}$, and this preparation was passed through a French pressure cell twice at 20000 p.s.i. (138 MPa). This preparation was centrifuged at $12000 \mathrm{~g}$ for $10 \mathrm{~min}$ at $4^{\circ} \mathrm{C}$, and the supernatant was used as the crude extract.

Purification of the intermediate. One-tenth volume concentrated $\mathrm{HCl}$ was added to crude extract from EMS12 grown on minimal medium with methylamine and methanol, and the mixture allowed to stand on ice for $20 \mathrm{~min}$. The resulting precipitate was removed by centrifugation at $12000 \mathrm{~g}$ for $10 \mathrm{~min}$ at $4{ }^{\circ} \mathrm{C}$. The $\mathrm{pH}$ of the supernatant was adjusted to 4.5 with $10 \mathrm{M} \mathrm{NaOH}$ and passed through a Sep-Pak $\mathrm{tC}_{18}$ vac, $10 \mathrm{~g}$ cartridge (Waters). The passed fraction was adjusted to $\mathrm{pH} 2$ and passed through another Sep-Pak $\mathrm{tC}_{18}$ vac cartridge. The intermediate adsorbed onto this cartridge and was eluted with $10 \%(\mathrm{v} / \mathrm{v})$ methanol. The fraction was adjusted to $\mathrm{pH} 6.5$ with $10 \mathrm{M} \mathrm{NaOH}$ and passed through a Sep-Pak QMA cartridge (Waters). This was then washed with $1 \mathrm{mM} \mathrm{HCl}$, and the intermediate was eluted with $100 \mathrm{mM} \mathrm{HCl}$. The eluted fraction was frozen at $-20^{\circ} \mathrm{C}$, dried with a Speed Vac concentrator without heating, and then dissolved in $5 \mathrm{mM} \mathrm{HCl}$. This fraction was analysed with a Hewlett Packard series II 1090 HPLC system equipped with a Hypersil BDS C-18 column $(250 \times 4 \mathrm{~mm}$, Hewlett Packard $)$. The eluent 
Table 1. Bacterial strains and plasmids

\begin{tabular}{|c|c|c|}
\hline Strain or plasmid & Relevant trait(s) & Source or reference \\
\hline \multicolumn{3}{|l|}{ E. coli } \\
\hline $\mathrm{DH} 5 \alpha$ & $\mathrm{r}^{-} \mathrm{m}^{+}$recA1 lacZYA $\phi 80 \mathrm{~d} l a c \Delta(\operatorname{lac} Z) M 15$ & Bethesda Research Laboratories \\
\hline S17-1 & recA thi pro & Simon et al. (1983) \\
\hline \multicolumn{3}{|l|}{ M. extorquens } \\
\hline AM1rif & & Nunn \& Lidstrom (1986) \\
\hline EMS12 & pqqC mutant of AM1rif & Morris et al. (1994) \\
\hline \multicolumn{3}{|c|}{ M. organophilum DSM 760} \\
\hline 452 & $p q q B$ & Biville et al. (1989) \\
\hline 474 & $p q q C$ & Biville et al. (1989) \\
\hline \multicolumn{3}{|l|}{ Plasmids } \\
\hline pRK310 & $\mathrm{Tc} c^{r} \mathrm{IncP} 1$ & Ditta et al. $\langle 1985\rangle$ \\
\hline pUC18/19 & $\mathrm{Ap}^{\mathrm{r}} \operatorname{lac} Z^{\prime}$ & Yanisch-Perron et al. (1985) \\
\hline pHT1KSac19f & $\begin{array}{l}\text { pUC19 containing } 1.3 \mathrm{~kb} K p n \mathrm{I}-\mathrm{SacI} \text { fragment } \\
(p q q C / D)\end{array}$ & This study \\
\hline pHT1KSac18 & $\begin{array}{l}\text { pUC18 containing } 1.3 \mathrm{~kb} K p n \mathrm{I}-S a c \mathrm{I} \text { fragment } \\
(p q q C / D)\end{array}$ & This study \\
\hline pHT1KSac & $\begin{array}{l}\text { pRK310 containing } 1.3 \mathrm{~kb} \text { Bam } \mathrm{HI}-P s t \mathrm{I} \text { fragment from } \\
\text { pHT1KSac19f }(p q q C / D)\end{array}$ & This study \\
\hline
\end{tabular}

used was $2 \%(\mathrm{v} / \mathrm{v})$ acetonitrile in distilled water adjusted to pH 2.5 with phosphoric acid. The peak corresponding to the intermediate was determined by collecting fractions and assaying them as described below.

Detection and assay of the intermediate. The intermediate was detected after conversion to PQQ with crude extract of E. coli DH5 $\alpha$ (pHT1KSac19f). The reaction was performed in $100 \mathrm{mM}$ Tris $/ \mathrm{HCl}(\mathrm{pH} 8.0)$ containing $1 \mathrm{mM}$ EDTA and $100 \mu \mathrm{M}$ NADPH at $30^{\circ} \mathrm{C}$. The crude extract was used in abundance $(10 \mu \mathrm{g}$ or more protein of the crude extract per $\mathrm{ml}$ in the reaction mixture) to ensure that the intermediate was converted to PQQ completely. The reaction was stopped by dilution into the PQQ assay mixture (see below).

Assay of PQQ. PQQ content was determined with the apoenzyme of soluble glucose dehydrogenase purified from E. coli containing the cloned gene from Acinetobacter calcoaceticus (Cleton-Jansen et al., 1989), which was a gift from $\mathrm{N}$. Goosen. Samples containing PQQ were incubated with the

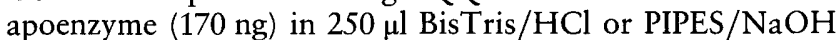
buffer ( $\mathrm{pH} 6.5$ ) containing $0 \cdot 1 \%$ Triton X-100 and $4 \mathrm{mM}$ calcium chloride for more than $5 \mathrm{~min}$ at room temperature. Then a $100 \mu \mathrm{l}$ portion was used to measure the activity spectrophotometrically as the reduction of phenazinemethosulfate and 2,6-dichlorophenol indophenol in $50 \mathrm{mM}$ potassium phosphate ( $\mathrm{pH} 6.5$ ) as described previously (Matsushita et al., 1995). The amount of PQQ was determined by comparison to a standard curve, generated with a PQQ solution whose concentration was checked by spectrophotometry using the molar absorption coefficient of $18400 \mathrm{M}^{-1} \mathrm{~cm}^{-1}$ at $249 \mathrm{~nm}$ (Duine et al., 1980). Protein concentration was determined by a modified Lowry method (Dulley \& Grieve, 1975).

Requirement for molecular oxygen. The reaction $(100 \mu \mathrm{l})$ was carried out at room temperature in a $2 \mathrm{ml}$ vial open or closed with a rubber stopper. The head space of the closed vial was flushed with nitrogen gas for $5 \mathrm{~min}$. The reaction was then started by addition of enzyme solution, which also had been flushed with nitrogen gas. Aliquots $(20 \mu \mathrm{l})$ were taken by microsyringe, added to the PQQ assay mixture, and the PQQ produced was assayed as described above.

\section{RESULTS AND DISCUSSION}

\section{Sequence analysis of pqq genes}

A $3.4 \mathrm{~kb}$ HindIII-PstI fragment of $M$. extorquens AM1 DNA known to complement $M$. extorquens AM1 and M. organophilum DSM 760 mutants in the PqqA complementation group (Morris et al., 1994), was sequenced on both strands to complete the sequence for the $p q q$ gene cluster (Fig. 1; Morris et al., 1994). The complementation analysis had suggested that this genomic region should contain three $p q q$ genes, $p q q C^{\prime} B A$ (Morris et al., 1994). However, only two ORFs were observed in the regions responsible for complementation of $p q q$ mutants: one in the $p q q C B$ region and one in the $p q q A$ region. Codon preference in these two ORFs was similar to that of the genes in $M$. extorquens AM1

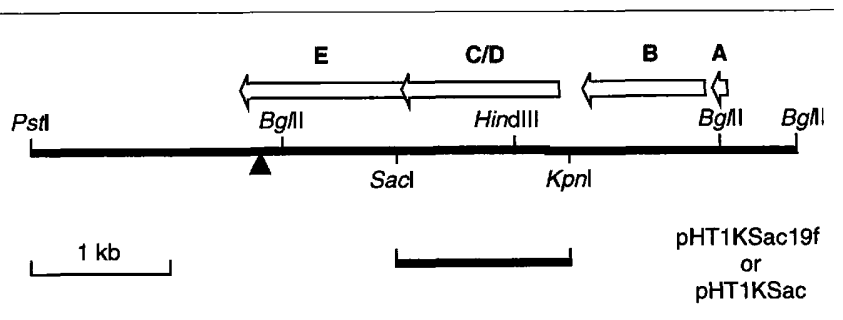

Fig. 1. Restriction map of the $5.5 \mathrm{~kb}$ fragment containing the pqqAB $(C / D) E$ region and the plasmids used in this study. Open arrows show ORFs of $p q q$ genes. The filled triangle represents the Tn5-6 insertion (Morris et al., 1994). 
Table 2. Correlation of Pqq complementation groups in different micro-organisms

\begin{tabular}{|cccc|}
\hline K. pneumoniae & A. calcoaceticus & $\begin{array}{c}\text { M. extorquens AM1 } \\
\text { (old) }\end{array}$ & $\begin{array}{c}\text { M. extorquens AM1 } \\
\text { (new) }\end{array}$ \\
\hline$p q q A$ & IV & $p q q D$ & $p q q A$ \\
$p q q B$ & V & $p q q G$ & $p q q B$ \\
$p q q C$ & I & $p q q C$ & $p q q C / D$ \\
$p q q D$ & II & $p q q B$ & $p q q C / D$ \\
$p q q E$ & III & $p q q A$ & $p q q E$ \\
$p q q F$ & - & $p q q E$ & $p q q F$ \\
- & - & $p q q F$ & $p q q G$ \\
\hline
\end{tabular}

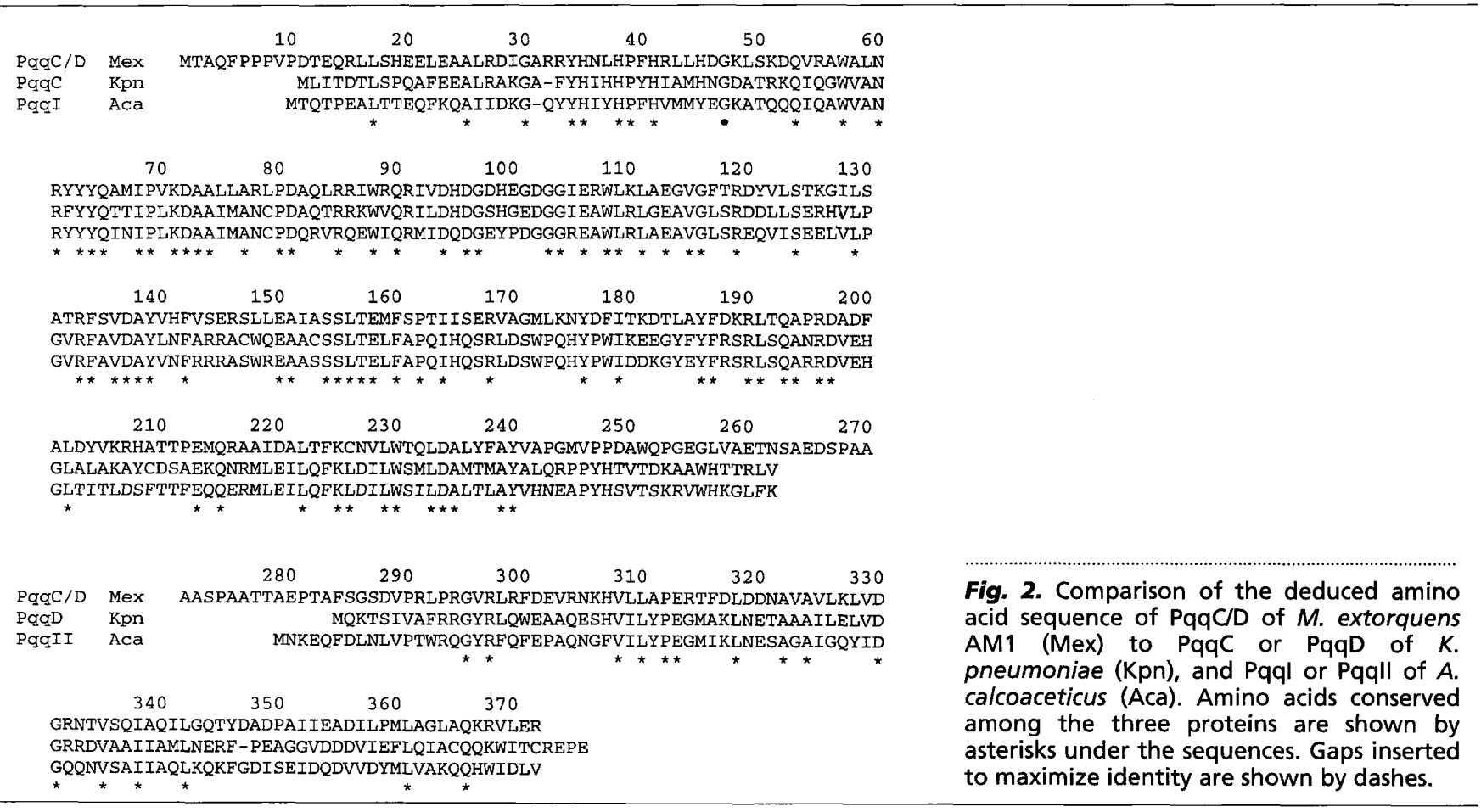

available in the database (data not shown). These data suggested that $p q q C$ and $p q q B$ might be fused in $M$. extorquens AM1. To facilitate comparison among $p q q$ genes of different micro-organisms, we propose to change the $p q q$ nomenclature for $M$. extorquens AM1 to follow that of $K$. pneumoniae (Table 2). Therefore, the newly found ORFs are designated $p q q C / D$ and pqqE.

The first ORF, $p q q C / D$, was predicted to be a 372 amino-acid polypeptide and its calculated molecular mass and isoelectric point were $41577 \mathrm{Da}$ and 5.73 , respectively. PqqC of $K$. pneumoniae and $\mathrm{PqqI}$ of $A$. calcoaceticus are composed of 251 and 252 amino acids, respectively, while PqqD of K. pneumoniae and PqqII of A. calcoaceticus are composed of 92 and 94 amino acids, respectively. Hence, the PqqC/D polypeptide is large enough to be a fusion of the two. Further supporting evidence for this idea came from sequence comparisons, which revealed that $\mathrm{PqqC} / \mathrm{D}$ showed significant identity to PqqC of $K$. pneumoniae $(44 \%)$ and PqqI of $A$. calcoaceticus (43\%) in its $\mathrm{N}$-terminus (residues 11-241,
Fig. 2). Likewise, the C-terminal portion (residues 285-366) showed significant identity to PqqD of $K$. pneumoniae (29\%) and PqqII of A. calcoaceticus (30\%). To determine whether the sequence was correct, and confirm that this region contained only one gene, SDSPAGE analysis was carried out on a crude extract of $E$. coli DH5 $\alpha$ cells containing pHT1KSac19f, the plasmid with a $1.3 \mathrm{~kb} \mathrm{KpnI-SacI}$ insert containing only $p q q C / D$ (Fig. 1). One significant, extra polypeptide band of around $42 \mathrm{kDa}$ appeared in the crude extract of these cells but not in the controls (Fig. 3), suggesting that only one gene of the indicated size was present in this region. These results show that in M. extorquens AM1, pqqC and $p q q D$ are fused into a single gene, which we propose to designate $p q q C / D$. This is consistent with the previous observation that no mutants of the PqqD complementation class were isolated from $M$. extorquens AM1 (Springer et al., 1995).

PqqE was predicted to consist of 384 amino acids. Its calculated molecular mass and isoelectric point were $41714 \mathrm{Da}$ and 6.42 , respectively. It shows high identity 


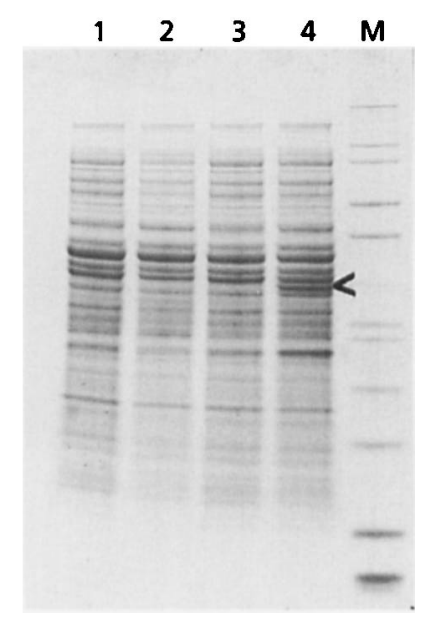

Fig. 3. SDS-PAGE of crude extract from $E$. coli containing different plasmids. Crude extract $(20 \mu \mathrm{g}$ protein) of $E$. coli harbouring pUC18, pHT1KSac18, pUC19 or pHT1KSac19f (lanes $1-4$, respectively) was analysed by SDS-PAGE using a precast Tricine gel $(10-20 \%$, NOVEX). Proteins were stained by Coomassie Brilliant Blue R250. The arrowhead indicates the band of $42 \mathrm{kDa}$, presumably corresponding to PqqC. Lane $\mathrm{M}$, Mark12 marker (NOVEX) containing 200, 116.3, 97.4, 66.3, 55.4, $36.5,31,21.5,14.4,6,3.5$ and 2.5 kDa proteins.

$(45-46 \%)$ in residues $17-358$ to $p q q$ gene products from other bacteria (Fig. 4). In addition, by using the BLASTP program, identity was observed to MoaA and other related proteins, $39-56 \%$ and $16-47 \%$ in residues $18-35$ and 55-92, respectively (see Table 3 ). Residues $28-45$ and 109-135 of PqqE also showed identity to NifB from Enterobacter agglomerans and $K$. pneumoniae (see Table 3). MoaA is a protein involved in an early step in the biosynthesis of the molybdopterin cofactor (Rajagopalan \& Johnson, 1992; Rivers et al., 1993) and NifB is involved in an early step in the biosynthesis of the cofactor of nitrogenases, FeMo-, FeV- and FeFe-cofactors. NifB has recently been shown to incorporate iron and sulfur from its metabolic product, termed NifB-co, to the cofactors of dinitrogenases (Allen et al., 1995), and it has been suggested that the role of this family of proteins is to donate metal atoms to the respective cofactor (Menendez et al., 1995). All of these sequences listed in Table 3 , including PqqE, contain a conserved $\mathrm{CxxxCxYC}$ sequence, which is proposed to anchor an iron-sulfur cluster or some type of metalbinding site (Menendez et al., 1995). MoaA proteins have a second cysteine-rich region in their C-terminus, with the motif $\mathrm{FCxxC}(13 \mathrm{x}) \mathrm{C}$ (Menendez et al., 1995). The C-terminal region of $\mathrm{PqqE}$ is also cysteine-rich and almost all of these cysteine residues were conserved in all the corresponding Pqq proteins (Fig. 4), although the motif was different from that of MoaA. If PqqE is involved in synthesis of a cofactor, the identity of the enzyme containing that cofactor is unknown.

It has previously been shown that one transposon insertion (Tn5-6) in p1130C, a plasmid containing $p q q\left(C^{\prime} / D\right) E$, can differentiate $p q q E$ of $M$. extorquens AM1 from the corresponding gene (previously called pqqA) of M. organophilum DSM 760. This insertion

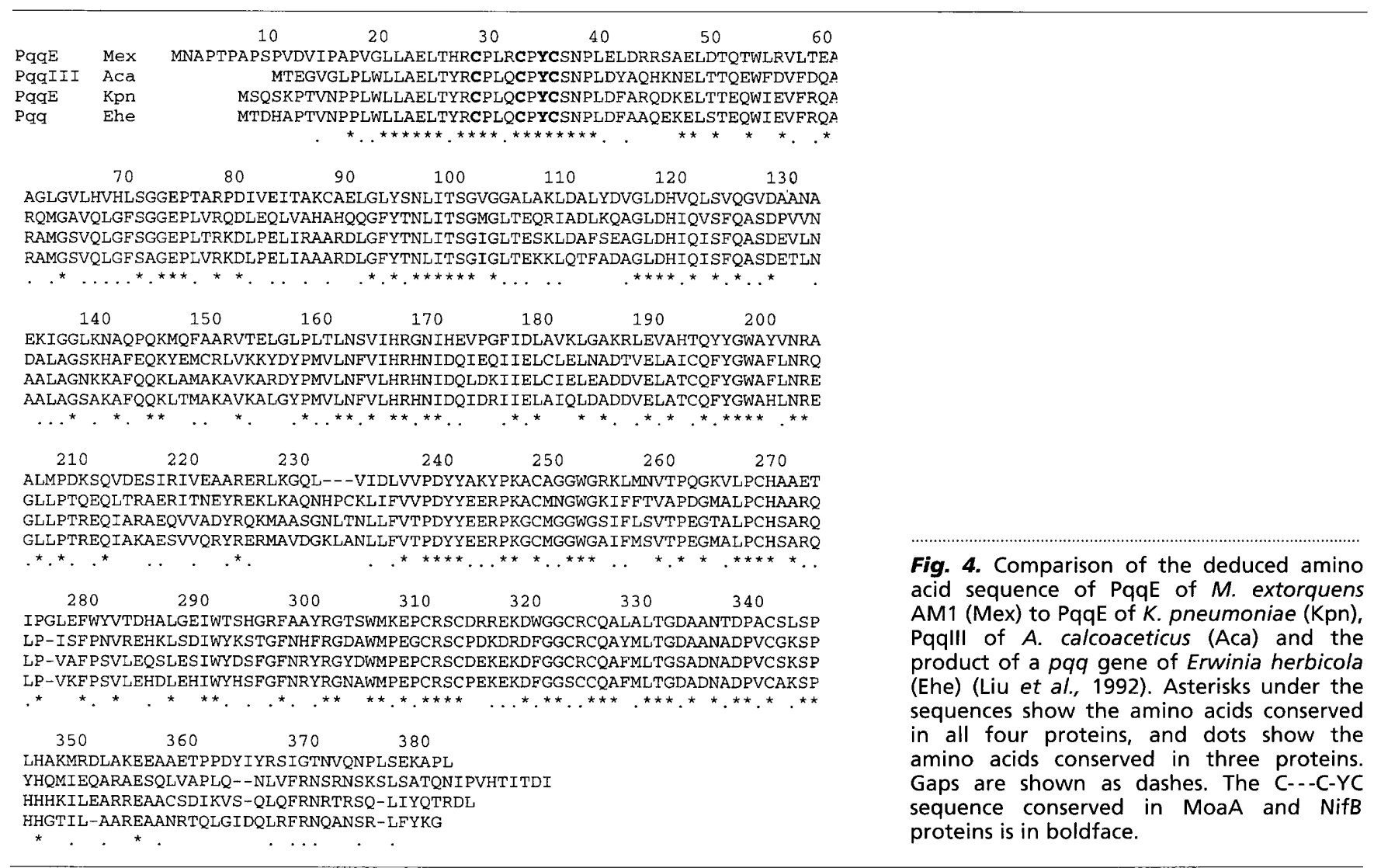


Table 3. Alignment of PqqE from M. extorquens $A M 1$ with the related pqq gene products, MoaA-related proteins and NifB

Homology analysis of PqqE was carried out using the BLASTP program in the GCG program. Only the region of interest is shown.

\begin{tabular}{|llrcc|}
\hline Protein & Organism & Position & Conserved domain & $\begin{array}{c}\text { Database } \\
\text { ref. }\end{array}$ \\
\hline PqqE & Mexto & $20-40$ & LLAELTHRCPLRCPYCSNPLE & U60993 \\
PqqE & Kpneu & $14-34$ & LLAELTYRCPLQCPYCSNPLD & X58778 \\
Pqq & Eherb & $14-34$ & LLAELTYRCPLQCPYCSNPLD & M94448 \\
PqqIII & Acalc & $11-31$ & LLAELTYRCPLQCPYCSNPLD & X06452 \\
Pqq? & Hinfl & $40-51$ & KCNLDCPWCDTP & U32798 \\
MoaA & Mther & $14-29$ & LRISVTGRCNVSCIYC & X87968 \\
Cnx2 & Athal & $77-92$ & LRISLTERCNLRCQYC & Z48047 \\
Moa & Celeg & $7-22$ & LRISLTEKCNFRCLYC & Z46267 \\
MoaA & Ecoli & $16-31$ & LRLSITDVCNFRCTYC & X70420 \\
MoaA & Anico & $47-58$ & LTDKCNLRCTYC & X78980 \\
Aor4 & Pfuri & $4-19$ & LYLEITSRCNLRCEMC & X79777 \\
MoaA & Hinfl & $25-40$ & LRLSITDQCNFRCTYC & U32840 \\
NarA & Bsubt & $19-34$ & LRISVTDRCNFRCTYC & Z35277 \\
NifB & Eagglo & $28-40$ & CNLQCNYCNRKYD & Z49943 \\
NifB & Kpneu & $54-66$ & CNLQCNYCNRKFD & M15545 \\
& & Consensus : & C---C-YC & \\
\hline
\end{tabular}

* Mexto, Metbylobacterium extorquens AM1: Kpneu, Klebsiella pneumoniae: Eherb, Erwinia berbicola: Acalc, Acinetobacter calcoaceticus: Hinfl, Haemophilus influenzae: Mther, Methanobacterium thermoautotrophicum: Athal, Arabidopsis thaliana: Celeg, Caenorhabditis elegans: Ecoli, Escherichia coli: Anico, Arthrobacter nicotinovorans: Pfuri, Pyrococcus furiosus: Bsubt, Bacillus subtilis: Eagglo, Enterobacter agglomerans.

complements $p q q E$ mutants of $M$. extorquens AM1 but not the pqqA mutant of $M$. organophilum DSM 760 (Morris et al., 1994). We determined the inserted position by sequencing $\mathrm{p} 1130 \mathrm{C}: \mathrm{Tn} 5-6$, and found that it occurred inside the ORF of $p q q E$, that is $23-25$ amino acids before the C-terminus (see Fig. 1), and that eight nucleotides were duplicated in both ends of the transposon. This C-terminal region is not conserved in these proteins (Fig. 4), and the site of the insertion suggests that this region is not necessary for PqqE function in $M$. extorquens AM1. However, this region is apparently important for function of the M. extorquens AM1 PqqE in M. organophilum DSM 760.

\section{Complementation analysis of mutants of M. organophilum DSM 760}

The $1.3 \mathrm{~kb} K p n \mathrm{I}-\mathrm{Sacl}$ fragment containing $p q q \mathrm{C} / \mathrm{D}$ (Fig. 1) complemented growth on methanol of $p q q C$ mutants of M. extorquens AM1 (mutant EMS12), and M. organophilum DSM 760 (mutant 474). However, growth on methanol of the $p q q D$ (previously $p q q B$ ) mutant of $M$. organophilum DSM 760 (mutant 452), was not complemented by the fragment although the subclone containing $p q q A B(C / D) E$ of $M$. extorquens AM1 did complement these mutants (Morris et al., 1994). The reason for this discrepancy is unknown, but the data suggest that in $M$. organophilum DSM 760 , functional expression of the PqqD portion of PqqC/D requires the presence of $p q q E$. No $p q q D$ mutants have been identified in M. extorquens AM1 (Springer et al., 1995).

\section{Production of an intermediate by the pqqC mutant and activity to convert the intermediate to PQQ in crude extract of $E$. coli cells}

Velterop et al. (1995) reported that E. coli cells containing a plasmid with all of the $p q q$ genes except $p q q C$ seemed to produce an intermediate of PQQ in both the culture medium and cells. This intermediate could be converted to biologically active PQQ by extracts containing only $\mathrm{PqqC}$, suggesting that PqqC catalyses the last step in PQQ synthesis. We examined production of an intermediate by a $p q q C$ mutant of $M$. extorquens AM1, EMS12 (Morris et al., 1994). Detection of the intermediate was assessed after its conversion to PQQ using a crude extact of $E$. coli harbouring pHT1KSac19f, producing PqqC/D (Fig. 3). Specific activity in the $E$. coli crude extract was estimated to be $20 \mathrm{pmol} \mathrm{min}^{-1}$ $(\mathrm{mg} \text { protein })^{-1}$ with $20 \mathrm{pmol}$ of the partially purified intermediate in a $20 \mu \mathrm{l}$ reaction mixture (see below). The activity was not observed in crude extract of $E$. coli containing the following controls: pUC18, pUC19 or $\mathrm{pHT} 1 \mathrm{KSac} 18$, in which the orientation of $p q q C / D$ to the lac promoter is opposite to $\mathrm{pHT} 1 \mathrm{KSac} 19 \mathrm{f}$. The $\mathrm{pH}$ 


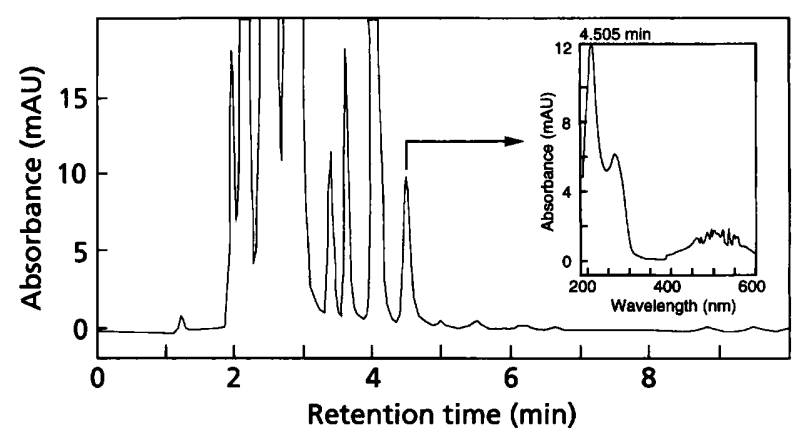

Fig. 5. HPLC profile and absorption spectrum of the intermediate. Partially purified intermediate (the amount estimated was $100 \mathrm{pmol}$ ) was analysed with a Hypersil BDS C18 column $(250 \times 4 \mathrm{~mm})$. The eluent used was $2 \%(\mathrm{v} / \mathrm{v})$ acetonitrile in distilled water adjusted $\mathrm{pH}$ to $\mathbf{2 . 5}$ with phosphoric acid. Flow rate was $1.0 \mathrm{ml} \mathrm{min}^{-1}$. mAU, milli-absorbance units.

optimum for this reaction was found to be around 8 . The intermediate was detected in both the culture medium and crude extract of EMS12, and estimated to be $20-80 \mathrm{nM}$ and $100-500 \mathrm{pmol}$ (mg protein) ${ }^{-1}$, respectively, in different batches, by using excess crude extract or incubating for longer periods. The total amount of the intermediate in crude extract was estimated to be slightly larger than that in the culture supernatant, 65-90 nmol (l culture $)^{-1}$, in contrast to the result in $K$. pneumoniae, where it was found mostly in the culture supernatant (Velterop et al., 1995). The amounts of this intermediate are apparently much higher in $M$. extorquens AM1 than in K. pneumoniae, as might be expected since the amount of PQQ produced is much higher in M. extorquens AM1 (Ramamoorthi \& Lidstrom, 1995) than in K. pneumoniae (Velterop et al., 1995).

\section{Purification of the intermediate}

The intermediate was expected to be similar to PQQ, since one enzyme, PqqC/D, could convert it to PQQ, suggesting it might contain three carboxyl groups. However, attempts to purify the intermediate from culture supernatant using anion-exchange columns failed because recovery of the activity was very low (data not shown). However, the intermediate adsorbed on a reversed-phase material, Sep-Pak $\mathrm{tC}_{18}$, at acidic $\mathrm{pH}$ near 2 , but not above $\mathrm{pH} 3$. These properties were used to design a purification scheme, starting with the crude extract of EMS12 (see Methods). Fig. 5 shows the chromatogram of HPLC analysis of the intermediate, and its absorption spectrum. The absorption maxima at $\mathrm{pH} 2.5$ were 218,274 and $520 \mathrm{~nm}$. This compound was stable at acidic $\mathrm{pH}$, but unstable at alkaline $\mathrm{pH}$ and to heat.

\section{Effect of EDTA, NAD(P)H and molecular oxygen}

The enzyme activity which converted the PQQ intermediate to PQQ was lowered after gel filtration with a Sephadex G-25 column or dialysis (data not shown),

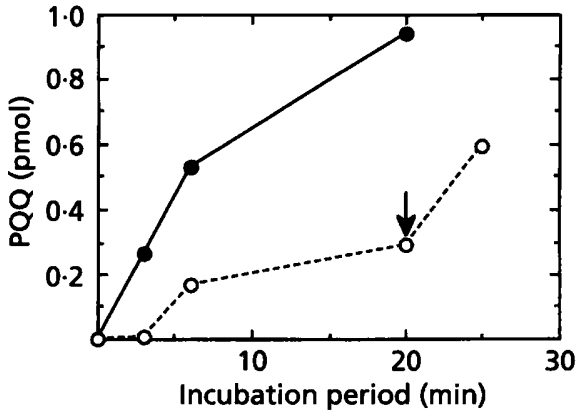

Fig. 6. Requirement for oxygen in the PqqC/D reaction. The reaction $(100 \mu \mathrm{l})$ was carried out in an open vial $(0)$ or a closed vial containing a nitrogen atmosphere (O). At the indicated times, a $20 \mu \mathrm{l}$ aliquot was taken by a microsyringe for assay (see text). The arrow indicates the time when the closed vial was opened to the air.

suggesting that the reaction required a low-molecularmass compound(s). This decreased activity was restored or even enhanced by the addition of NADH or NADPH in the presence of EDTA. Without EDTA, NAD $(\mathrm{P}) \mathrm{H}$ showed an inhibitory effect in high concentration $(1 \mathrm{mM})$. The reaction was saturated for NADPH at $100 \mu \mathrm{M}$, and $\mathrm{NADH}$ at $500 \mu \mathrm{M}$.

An apparent requirement of molecular oxygen for the reaction was observed. If the reaction was carried out under a nitrogen atmosphere in a $2 \mathrm{ml}$ vial closed with a rubber stopper, production of PQQ was substantially reduced, to about $20 \%$ of that in an open vial (Fig. 6). Normal production of PQQ was recovered after opening the vial to air (Fig. 6). Sodium cyanide and sodium azide ( $2 \mathrm{mM}$ each) did not affect the activity.

These data imply that PqqC/D may be a monooxygenase or dioxygenase. However, the PqqC/D sequence does not show identity to any monooxygenases or dioxygenases in the database. Confirmation of the reaction will require determination of the structure of the intermediate, purification of $\mathrm{PqqC} / \mathrm{D}$, and investigation of its biochemical characteristics. These sets of experiments are now in progress.

\section{ACKNOWLEDGEMENTS}

This research was supported by a grant from the NIH (GM36294). H. T. was supported by Postdoctoral Fellowships for Research Abroad from the Japan Society of the Promotion of Science.

\section{REFERENCES}

Allen, R. M., Chatterjee, R., Ludden, P. W. \& Shad, V. K. (1995). Incorporation of iron and sulfur from $\mathrm{NifB}$ cofactor into the ironmolybdenum cofactor of dinitrogenase. J Biol Chem 270, 26890-26896.

Anthony, C. (1993). The role of quinoproteins in bacterial energy transduction. In Principles and Applications of Quinoproteins, pp. 223-244. Edited by V. L. Davidson. New York: Marcel Dekker. 
Biville, F., Turlin, E. \& Gasser, F. (1989). Cloning and genetic analysis of six pyrroloquinoline quinone biosynthesis genes in Methylobacterium organophilum DSM760. J Gen Microbiol 135, 2917-2929.

Cleton-Jansen, A.-M., Goosen, N., Vink, K. \& Putte, P. v. d. (1989). Cloning, characterization and DNA sequencing of the gene encoding the $M_{r} 50,000$ quinoprotein glucose dehydrogenase from Acinetobacter calcoaceticus. Mol Gen Genet 217, 430-436.

Ditta, G., Schmidhauser, T., Yakobson, E., Lu, P., Liang, X.-W., Finlay, D. R., Guiney, D. \& Helinski, D. R. (1985). Plasmids related to the broad host range vector pRK290, useful for gene cloning and for monitoring gene expression. Plasmid 13, 149-153.

Duine, J. A., Frank, J. \& Verwiel, P. E. J. (1980). Structure and activity of the prosthetic group of methanol dehydrogenase. Eur $J$ Biochem 108, 187-192.

Dulley, J. R. \& Grieve, P.A. (1975). A simple technique for eliminating interference by detergents in the Lowry method of protein determination. Anal Biochem 64, 136-141.

Goosen, N., Horsman, H. P. A., Huinen, R. G. M. \& Putte, P. V. D. (1989). Acinetobacter calcoaceticus genes involved in biosynthesis of the coenzyme pyrrolo-quinoline-quinone: nucleotide sequence and expression in Escherichia coli K-12. J Bacteriol 171, 447-455.

Goosen, N., Huinen, R. G. M. \& Putte, P. V. D. (1992). A 24-aminoacid polypeptide is essential for the biosynthesis of the coenzyme pyrrolo-quinoline-quinone. J Bacteriol 174, 1426-1427.

Houck, D. R., Hanners, J. L. \& Unkefer, C. J. (1991). Biosynthesis of pyrroloquinoline quinone. 2. Biosynthetic assembly from glutamate and tyrosine. J Am Chem Soc 113, 3162-3166.

van Kleef, M. A. G. \& Duine, J. A. (1988). L-Tyrosine is the precursor of PQQ biosynthesis in Hyphomicrobium X. FEBS Lett 237, 91-97.

Liu, S.-T., Lee, L.-Y., Tai, C.-Y., Hung, C.-H., Chang, Y.-S., Wolfram, J. H., Rogers, R. \& Goldstein, A. H. (1992). Cloning of an Erwinia berbicola gene necessary for gluconic acid production and enhanced mineral phosphate solubilization in Escherichia coli HB101: nucleotide sequence and probable involvement in biosynthesis of the coenzyme pyrroloquinoline quinone. J Bacteriol 174, 5814-5819.

Matsushita, K. \& Adachi, O. (1993). Bacterial quinoprotein dehydrogenases, glucose dehydrogenase and alcohol dehydrogenase. In Principles and Applications of Quinoproteins, pp. 47-64. Edited by V. L. Davidson. New York: Marcel Dekker.

Matsushita, K., Toyama, H., Ameyama, M., Adachi, O., Dewanti, A. \& Duine, J. A. (1995). Soluble and membrane-bound quinoprotein D-glucose dehydrogenases of Acinetobacter calcoaceticus: the binding process of the apoenzymes. Biosci Biotech Biochem 59, 1548-1555.

Menendez, C., Igloi, G., Henninger, H. \& Brandsch, R. (1995). A pAO-1-encoded molybdopterin cofactor gene (moaA) of Arthrobacter nicotinovorans: characterization and site-directed mutagenesis of the encoded protein. Arch Microbiol 164, 142-151.
Meulenberg, J. J. M., Sellink, E., Riegman, N. H. \& Postma, P. W. (1992). Nucleotide sequence and structure of the Klebsiella pneumoniae pqq operon. Mol Gen Genet 232, 284-294.

Morris, C. J., Biville, F., Turlin, E., Lee, E., Ellermann, K., Fan, W.-H., Ramamoorthi, R., Springer, A. L. \& Lidstrom, M. E. (1994). Isolation, phenotypic characterization and complementation analysis of mutants in Methylobacterium extorquens AM1 unable to synthesize pyrroloquinoline quinone and sequence of $p q q D$, $p q q G$, and pqqC. J Bacteriol 176, 1746-1755.

Nunn, D. N. \& Lidstrom, M. E. (1986). Isolation and complementation analysis of 10 methanol oxidation mutant classes and identification of the methanol dehydrogenase structural gene of Methylobacterium sp. strain AM1. J Bacteriol 166, 581-590.

Rajagopalan, K. V. \& Johnson, J. L. (1992). The pterin molybdenum cofactors. J Biol Chem 267, 10199-10202.

Ramamoorthi, R. \& Lidstrom, M. E. (1995). Transcriptional analysis of $p q q D$ and study of the regulation of pyrroloquinoline quinone biosynthesis in Methylobacterium extorquens AM1. J Bacteriol 177, 206-211.

Rivers, S. L., McNairn, E., Blasco, F., Giordano, G. \& Boxer, D. H. (1993). Molecular genetic analysis of the moa operon of Escherichia coli $\mathrm{K}-12$ required for molybdenum cofactor biosynthesis. Mol Microbiol 8, 1071-1081.

Sambrook, J., Fritsch, E. F. \& Maniatis, T. (1989). Molecular Cloning: a Laboratory Manual, 2nd edn. Cold Spring Harbor, NY: Cold Spring Harbor Laboratory.

Schnider, U., Keel, C., Voisard, C., Defago, G. \& Haas, D. (1995). Tn5-directed cloning of $p q q$ genes from Pseudomonas fluorescens CHA0: mutational inactivation of the genes results in overproduction of the antibiotic pyoluteorin. Appl Environ Microbiol 61, 3856-3864.

Simon, R., Priefer, U. \& Puhler, A. (1983). A broad host range mobilization system for in vivo genetic engineering: transposon mutagenesis in Gram negative bacteria. Bio/Technology 1, 784-791.

Springer, A. L., Chou, H.-H., Fan, W.-H., Lee, E. \& Lidstrom, M. E. (1995). Methanol oxidation mutants in Methylobacterium extorquens AM1: identification of new genetic complementation groups. Microbiology 141, 2985-2993.

Velterop, J. S., Sellink, E., Meulenberg, J. J. M., David, S., Bulder, I. \& Postma, P. W. (1995). Synthesis of pyrroloquinoline quinone in vivo and in vitro and detection of an intermediate in the biosynthetic pathway. J Bacteriol 177, 5088-5098.

Yanisch-Perron, C., Vieira, J. \& Messing, J. (1985). Improved M13 phage cloning vectors and host strains: nucleotide sequences of the M13mp18 and pUC19 vectors. Gene 33, 103-119.

Received 24 June 1996; revised 24 September 1996; accepted 30 September 1996. 